Research Article

\title{
Uplift Bearing Capacity of Transmission Tower Foundation in Reinforced Aeolian Sand Using Simplified Model Tests
}

\author{
Shijun Ding $\mathbb{D}^{1,2}$ Yongfeng Cheng, ${ }^{2}$ Hong Zheng, ${ }^{1}$ Feng Xue, ${ }^{3}$ Zhibao Nie, ${ }^{2}$ and Yin Man ${ }^{2}$ \\ ${ }^{1}$ Key Laboratory of Urban Security and Disaster Engineering, Ministry of Education, Beijing University of Technology, \\ Beijing 100124, China \\ ${ }^{2}$ Geotechnical Engineering Laboratory, China Electric Power Research Institute, Beijing 102401, China \\ ${ }^{3}$ State Grid Qinghai Electric Power Corporation, Xining 810008, China \\ Correspondence should be addressed to Shijun Ding; dingsj@epri.sgcc.com.cn
}

Received 16 December 2020; Revised 26 April 2021; Accepted 8 July 2021; Published 23 July 2021

Academic Editor: André Furtado

Copyright (C) 2021 Shijun Ding et al. This is an open access article distributed under the Creative Commons Attribution License, which permits unrestricted use, distribution, and reproduction in any medium, provided the original work is properly cited.

\begin{abstract}
In order to analyze the uplift bearing capacity of transmission tower foundation in the geosythetic-reinforced aeolian sand, a series of simplified indoor modeling tests are carried out. A simplified reduced-scale foundation made according to the prototype and the uplift bearing capacity of transmission tower foundation in geosynthetic-reinforced aeolian sand is studied. Three kinds of reinforcement materials are embedded in the sand according to five ways of layout spacing. A total of 15 reinforcement schemes are tested. The results show that ultimate uplift bearing capacity of transmission tower foundation can be significantly improved by the reinforcement treatment of geotechnical materials in the aeolian sand. The type and spacing of reinforced materials also have a significant influence on the uplift bearing capacity of the foundation model in reinforced aeolian sand, and the effect of reinforcement works until the end of the loading process. The comprehensive effect is evaluated by the ratio of bearing capacity improvement and the total layer of reinforced materials. Based on the above results, the bearing mechanism of transmission tower foundation in geosynthetic-reinforced aeolian sand is elaborated and analyzed in detail.
\end{abstract}

\section{Introduction}

The transmission corridors with good terrain, transportation, geology, and other construction conditions are becoming scarce resources. More transmission lines are located in mountains, deserts, and so on. For example, in China, the West-East Electricity Transmission Project, the power transmission project in Xinjiang and Inner Mongolia will inevitably pass through desert areas. Aeolian sand has a loose state, and its shear resistance is poor. But the ground composed of aeolian sand usually has good compression performance. In the design of many foundations, it is necessary to evaluate the uplift bearing capacity of the sand, especially for transmission tower and many communication tower projects. In these cases, the requirement for uplift resistance is due mainly to high overturning loads imposed by wind or line tension [1], which often determines the size of the foundation, resulting in a great safety margin of the compressive bearing capacity of aeolian sand and poor economy of the foundation construction. Simultaneously, due to the poor self-supporting stability of aeolian sand, the excavation area of the foundation pit is large, and the earthwork volume is large (see Figure 1). While making full use of its compressive capacity, the uplift stability is often insufficient. It is a technical requirement to improve the uplift resistance of aeolian sand by foundation treatments.

The beneficial effects of using geosynthetics to increase the bearing capacity of foundation have been clearly demonstrated by previous studies [2-9]. Dash et al. [10] carried out indoor model tests on the reinforcement of sand bedsupport strip foundation with geogrid cushion and determined the layout depth, size of the geogrid layer, and the optimal length width ratio of geogrid bag supported strip foundation. Yuan et al. [11] conducted a comparative study on the antideformation performance of the independent foundation and composite foundation with protecting apron 


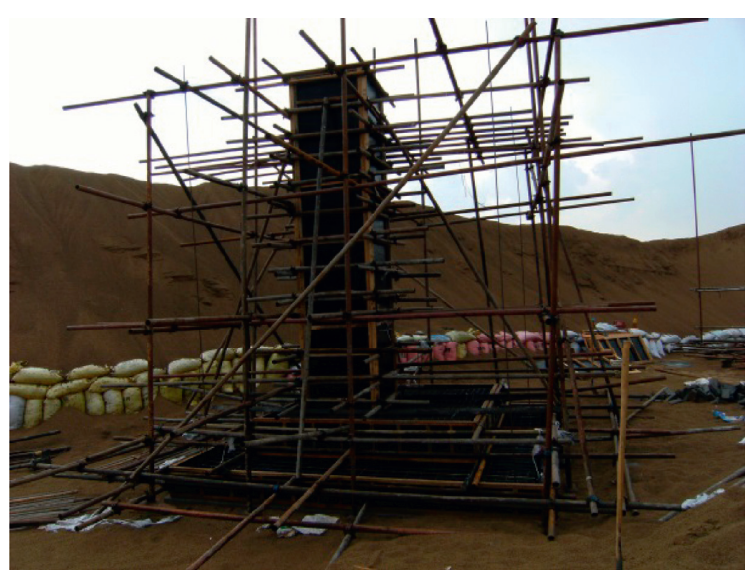

(a)

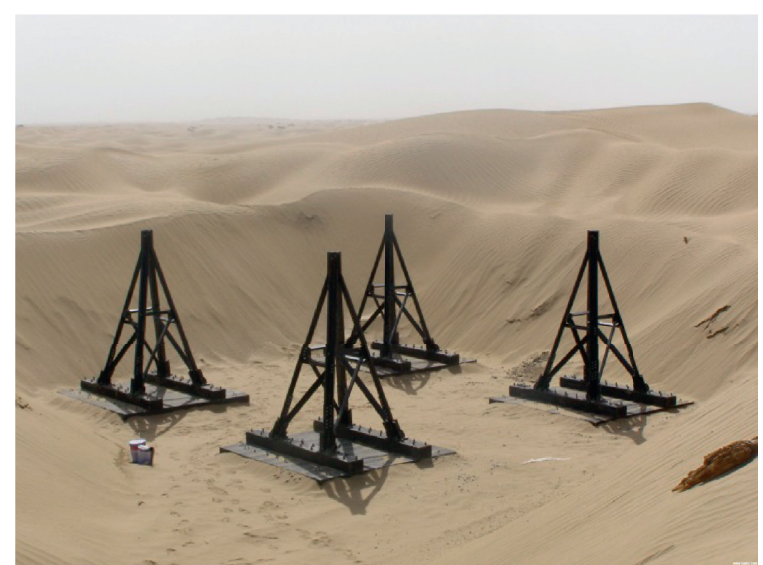

(b)

FIGURE 1: Foundation construction in desert.

by finite element simulation. Kouzer and Kumar [12, 13] studied the vertical uplift capacity of anchors in the sand by using the upper bound theorem of limit analysis combined with finite element analysis and linear programming. Tafreshi and Dawson [14] investigated the performance of geogrids and plane reinforcement in the range of low to medium settlement levels. Subsequently, a series of laboratory model load tests under a combination of static and repeated compressive and tensile loads were carried out with a belled pile supported on reinforced and unreinforced geocell-soil beds [15]. It was concluded that adding geogrids to the foundation can improve the upper and lower displacements and uplift stability. Abu-Farsakh et al. [16] presented the influence of different geosynthetic parameters on the bearing performance. The test results show that the use of geosynthetic-reinforced sand foundation has potential benefits. Keskin [17] has conducted an experimental study on the uplift capacity of reinforced and unreinforced horizontal square plate bolts. Tavangar and Shooshpasha [18] carried out plate load tests with square plates of different sizes and studied the influence of the first layer depth, vertical spacing, and number of layers of geotextile on the ultimate bearing capacity of the foundation. Cicek et al. [19] investigated the influence of the first reinforcement layer depth through indoor plate load test and finite element model analysis, and the effective depth of the first reinforcement layer is obtained. Ghosh and Bera [20] investigated the effect of the geotextile ties on the uplift capacity of anchors embedded in sand. Boushehrian et al. [21] conducted a numerical study on the load-carrying behavior of the soil reinforced with geogrid and grid-anchor under cyclic loading. Das and Bera [22] numerically investigated the ultimate uplift capacity of the bell-shaped anchor in river sand. The results reveal that the ultimate uplift capacity of the anchor increases with the increase of the ratio of embedment depth to bell diameter, while the ultimate uplift capacity is irrelevant to the friction angle of the soil and the anchor diameter. However, the studies pertaining to the anchor buried in the reinforced soil are rarely seen, which motivates the present study to conduct an experimental study on the uplift load-carrying capacity of the anchor buried in the reinforced soil for transmission towers.

The transmission tower foundation in the aeolian sand usually selects plate foundation, which mainly uses the shear bearing capacity and weight of the soil above the foundation slab to resist uplift load. At present, the research on the reinforcement of aeolian sand is merely reported. With the increase of the transmission line engineering application, it is necessary to analyze the reinforcement mechanism of aeolian sand and study more improvement methods to reinforce the ground. To explain the influence of reinforced materials and the spacing of reinforced materials in aeolian sand on the uplift bearing capacity of transmission tower foundation, indoor model tests of the expanded foundation of aeolian sand-reinforced composite foundation under different factors are performed. Based on the test load and displacement, the bearing performance is analyzed, and the influence of material properties and spacing of reinforcement material on the bearing process of the foundation is studied. The response characteristics provide a reference for the design and application of aeolian sand-reinforced composite ground in transmission line engineering.

\section{Simplified Modeling Test}

2.1. Simplified Foundation Model and Sand Properties. In this study, the indoor model tests of the plate foundation in aeolian sand-reinforced composite ground with different materials and vertical spacing of reinforcement layers are conducted.

In the test, the model tank is a rectangular frame with PMMA panels arranged on the side and bottom, so as to facilitate the observation of the loading process. The structure of the model tank is shown in Figure 2, in which the name of each element involved in the experiment has been marked.

Aeolian sand from the desert and its reinforced composite soil are used as the uplift ground in the model tank, and the tested soil is from the aeolian sand in Taklimakan Desert of China. The aeolian sand weight of the backfill 


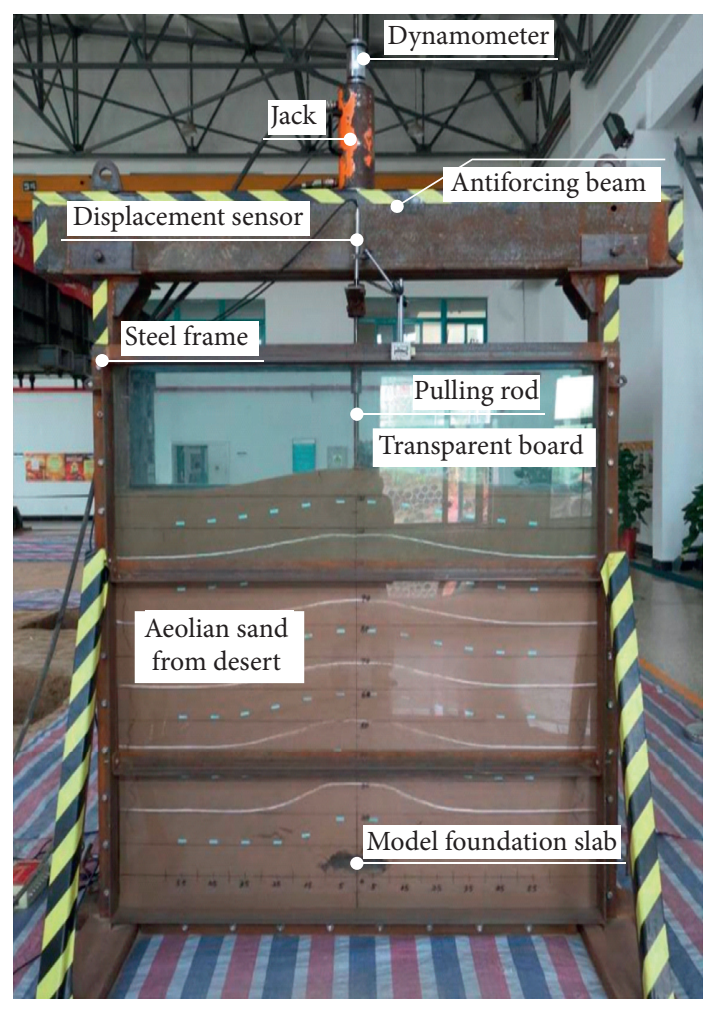

FIGURE 2: Model tank and foundation model.

ground is $14.2 \mathrm{kN} / \mathrm{m}^{3}$, the internal friction angle is $35.4^{\circ}$, and the moisture content is $3.5 \%$. The particle size distribution curve of aeolian sand obtained by the particle analysis test is shown in Figure 3. The particle size composition is mainly concentrated in $0.1 \mathrm{~mm}-0.25 \mathrm{~mm}$, accounting for $98.7 \%$ of the sample mass. According to the Unified Soil Classification System (USCS) chart, the soil should be categorized as SP. Since the particle size of aeolian sand is relative concentrated, the density can be well ensured by controlling the water content and backfill process.

2.2. Test Devices and Monitoring Apparatuses. The test foundation model consists of a steel plate and a round steel bar, as shown in Figure 4. In the test, the round steel bar connected with the model steel plate is applied with a oneway uplift load. The load and displacement values during the loading process are monitored. Vibrating chord load sensors and displacement sensors are used for load and displacement monitoring, respectively. The accuracy of vibrating chord load sensors is $0.01 \mathrm{kN}$ and that of displacement sensors is $0.01 \mathrm{~mm}$. There are two displacement measuring points symmetrically deployed on the upper part of the round steel.

\subsection{Reinforcement Schemes and Loading Process. To improve} the uplift bearing capacity of the transmission tower foundation buried in the aeolian sand, reinforced geotechnical materials are arranged horizontally in the aeolian sand above the foundation slab. The layout spacing is shown in Figure 5. In the tests, three kinds of geosynthetics are used to improve the uplift performance of the aeolian sand

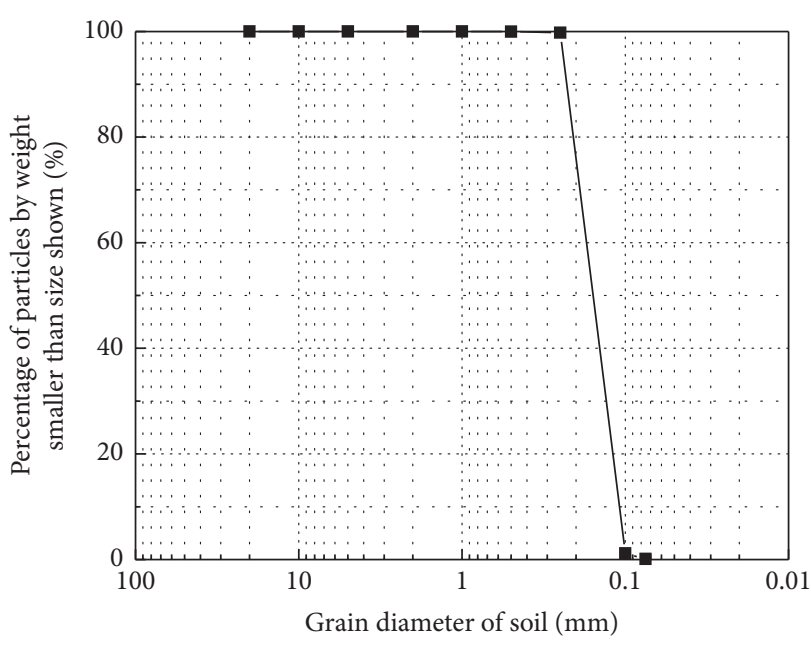

Figure 3: Grading curve of aeolian sand particles.

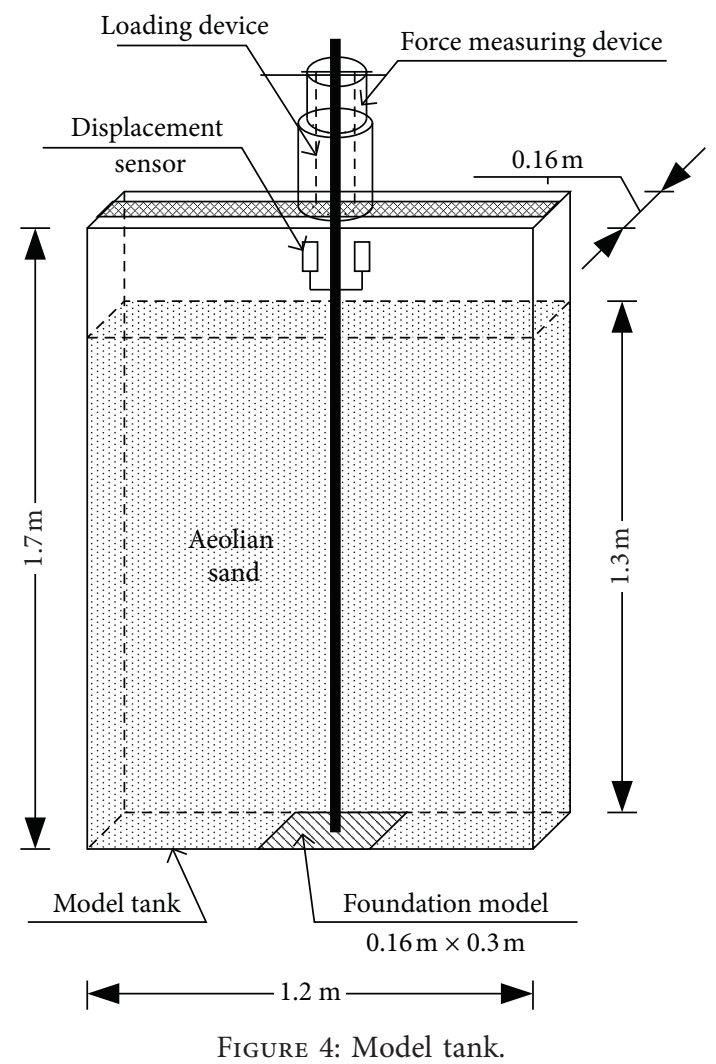

foundation, namely, biaxial plastic geogrid (BPG), steel plastic geogrid (SPG), and geotextile. The materials are from a geosynthetic material company named "Hefei Ruibang Engineering Materials Co., Ltd," located in Anhui Province, China. Among them, the SPG grid warp and weft strip are formed by high-strength steel wire and polypropylene attached on its surface, which has the characteristics of higher strength and higher bearing capacity. And, the vertical layout spacing is $b_{j}$. The basic performance indexes of materials are shown in Table 1 . The material parameters in Table 1 are provided by the manufacturer obtained by detection tests. 


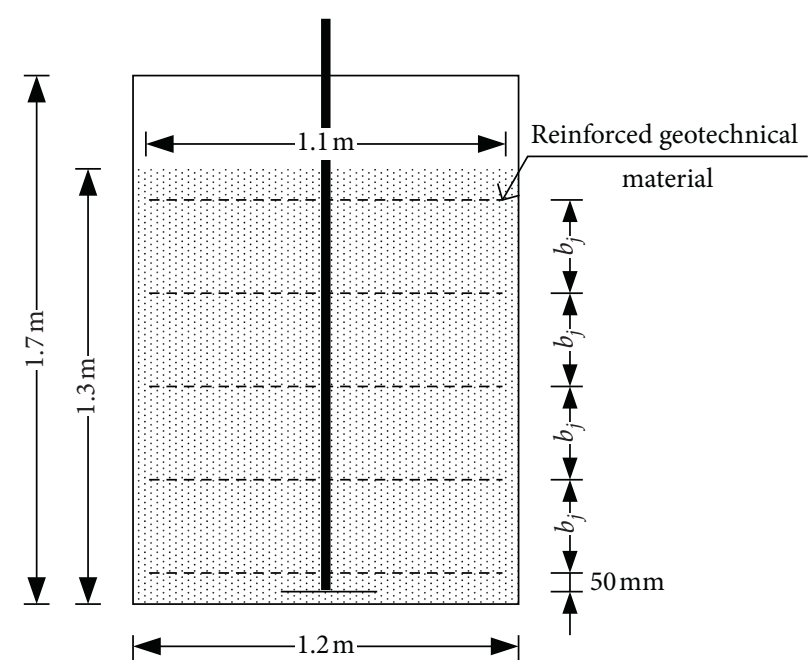

Figure 5: Reinforcement layout.

TABLE 1: Fundamental characteristics of reinforced geotechnical materials.

\begin{tabular}{lll}
\hline Reinforced geotechnical material & SPG & Geotextile \\
\hline Ultimate tensile strength (kN/m) & Elongation at nominal tensile strength (\%)
\end{tabular}

In the tests, the influence of two factors, $A$ (geotechnical material) and $B$ (layout spacing), on the uplift bearing capacity of the composite soil and foundation model are investigated. Among them, three different reinforcement materials are selected for factor $A$, which are BPG $\left(a_{1}\right)$, SPG $\left(a_{2}\right)$, and geotextile $\left(a_{3}\right)$; the whole factor $B$ includes five layouts' spacing $b_{j}$, which are $50 \mathrm{~mm}\left(b_{1}\right), 100 \mathrm{~mm}\left(b_{2}\right)$, $150 \mathrm{~mm}\left(b_{3}\right), 200 \mathrm{~mm}\left(b_{4}\right)$, and $300 \mathrm{~mm}\left(b_{5}\right)$. An experiment is performed under each level combination. The experiment with factor $A$ taking level $i$ and factor $B$ taking level $j$ is recorded as $T_{\mathrm{ij}}$. The experimental design information is described in Table 2. As a control, the uplift bearing capacity test of a foundation model in unreinforced aeolian sand is added, which is recorded as $T_{0}$. A total of 15 experiments are carried out.

The maintaining displacement mode is used during the test loading process. When the predetermined displacement value of each stage is reached, the uplift load remains unchanged and the displacement is maintained for $5 \mathrm{~min}$. The load and displacement values are recorded at least three times. The last load value measured during the maintenance of each displacement level is regarded as the bearing capacity of the model, and the maximum displacement of the test is not less than $100 \mathrm{~mm}$. The predetermined displacement
TABLE 2: Basic information of the test sample.

\begin{tabular}{lccccc}
\hline & \multicolumn{5}{c}{ Factor $B$} \\
Factor $A$ & $b_{1}: 50$ & $b_{2}: 100$ & $b_{3}: 150$ & $b_{4}: 200$ & $b_{5}: 300$ \\
\hline$a_{1}:$ BPG & $T_{11}$ & $T_{12}$ & $T_{13}$ & $T_{14}$ & $T_{15}$ \\
$a_{2}$ : SPG & $T_{21}$ & $T_{22}$ & $T_{23}$ & $T_{24}$ & $T_{25}$ \\
$a_{3}$ : geotextile & $T_{31}$ & $T_{32}$ & $T_{33}$ & $T_{34}$ & - \\
\hline
\end{tabular}

values are graded as follows: $2 \mathrm{~mm}, 6 \mathrm{~mm}, 12 \mathrm{~mm}, 22 \mathrm{~mm}$, $37 \mathrm{~mm}$, and an additional $15 \mathrm{~mm}$ increase for each subsequent stage. It should be noted that the uplift deformation is generally small at the working load to ensure the safety of the upper structures. Therefore, the loading process is ceased at an uplift displacement of $120 \mathrm{~mm}$ in the loading test, which is large enough to cover the uplift displacement that would happen for most cases.

Many studies have been conducted on the ultimate uplift capacity of foundations [23-25]. Most approaches involve the use of either limit equilibrium concepts or the method of characteristics and frequently combined with empirical corrections [26-28]. The ultimate bearing capacity of transmission line foundation usually corresponds to the maximum uplift load. However, the indoor model test shows 
that the uplift load still increases even at a very larger uplift displacement. Therefore, in this study, the second inflection point method proposed by Polous and Davis [29], the uplift load corresponding to the displacement at the onset of the final linear region of the load-displacement curve, is used to determine the ultimate uplift capacity. Liu et al. [30] and Kulhawy and Hirany [31] also used this method to determine the ultimate bearing capacity of spread foundation and drilled piles.

\section{Test Results and Discussion}

3.1. Relationship between Uplift Load and Displacement. According to the uplift load and displacement values measured by the tests, the curves of load and displacement at the different vertical layout spacing are presented in Figure 6. The uplift load value is the bearing capacity of the foundation in the corresponding state.

It can be seen that the loading process curves do not have the characteristics of steep drop, and no peak bearing capacity and bearing capacity weakening are observed. There are two inflection points in the curves, at the point where the displacements are $2 \mathrm{~mm}$ and $52 \mathrm{~mm}$, respectively. The loading process is divided into three stages: the linear curve section from 0 to $2 \mathrm{~mm}$, the nonlinear curve section from $2 \mathrm{~mm}$ to $52 \mathrm{~mm}$, and the linear curve section greater than $52 \mathrm{~mm}$.

When the displacement is less than or equal to $2 \mathrm{~mm}$, the interaction between the foundation and aeolian sand ground is in the elastic deformation stage, and the reinforced materials begin to provide uplift resistance. With the increase of displacement (from $2 \mathrm{~mm}$ to $52 \mathrm{~mm}$ ), the aeolian sand ground gradually exhibits the plastic state, and the uplift reinforcement effect of reinforced materials is gradually enhanced. As the displacement continues to increase, the increment of bearing capacity is mainly provided by the reinforced material, and the curve is approximately linear.

When the layout spacing is $50 \mathrm{~mm}, 100 \mathrm{~mm}$, and $200 \mathrm{~mm}$, the load and displacement curves of the model tests with different reinforced composite foundation and unreinforced aeolian sand foundation are shown in Figure 7.

The end of uplift load and displacement curves is approximate parallel, and the reinforcement effect is analyzed. The smaller the spacing, the earlier the uplift reinforcement effect of the reinforcement material and the shorter the curve section of the reinforcement effect. When the spacing is $50 \mathrm{~mm}$ and the displacement reaches $22 \mathrm{~mm}$, the reinforcement effect is very obvious. While the spacing is $100 \mathrm{~mm}$, the displacement needs to reach $37 \mathrm{~mm}$ to show reinforcement effect. Moreover, the smaller the spacing, the closer the ultimate bearing capacity of BPG and SPG.

3.2. Ultimate Uplift Capacity. According to the relationship curves between uplift load and displacement, the second inflection point method is used to determine the ultimate bearing capacity of the model test. The second inflection point of the present tests is at the displacement of $52 \mathrm{~mm}$, and the ultimate bearing capacity of the tests is regarded as the corresponding uplift load. The test results of the ultimate bearing capacity are demonstrated in Table 3 . The value of $K$ in Table 3 is the ratio of the ultimate bearing capacity of a model foundation in the reinforced composite soil and in the unreinforced aeolian sand. It can be seen that the maximum $K$ value is 1.43 , and the ultimate uplift bearing capacity of the foundation can be significantly improved with the reinforcement of geotechnical materials in the aeolian sand. The BPG has the best uplift bearing capacity when the same spacing of geotechnical materials is used. Although the mechanical properties of the SPG grid strip are better than the BPG, the grid size of BPG is $40 \mathrm{~mm} \times 40 \mathrm{~mm}$ and BPG is $80 \mathrm{~mm} \times 80 \mathrm{~mm}$, leading to a greater $K$ of SPG than that of BPG. The smaller the layout spacing of the same geotechnical material, the better the ultimate bearing capacity's improvement effect.

It is also interesting to see that the ultimate bearing capacity of the reinforced foundation is smaller than that of the unreinforced foundation. The bearing capacity increase ratio can be calculated as follows: (bearing capacity after reinforcement-bearing capacity without reinforcement)/ bearing capacity without reinforcement $\times 100 \%$. As can be illustrated by the results in Table 3, when the ultimate deformation is $52 \mathrm{~mm}$, as for interval spaces of $50 \mathrm{~mm}$, $100 \mathrm{~mm}, 150 \mathrm{~mm}, 200 \mathrm{~mm}$, and $300 \mathrm{~mm}$, the increase ratios of $\mathrm{BPG}$ are $43 \%, 36 \%, 28 \%, 23 \%$, and $10 \%$, respectively. Corresponding increase ratios of SPG are $41 \%, 30 \%, 18 \%$, $13 \%$, and $4 \%$, respectively. The increase ratios of geotextile are $15 \%, 7 \%, 4 \%$, and $-2 \%$ when the interval spaces were $50 \mathrm{~mm}, 100 \mathrm{~mm}, 150 \mathrm{~mm}$, and $200 \mathrm{~mm}$. However, the uplift displacement required to fully mobilize the ultimate strength of the reinforced foundation exceeds the final uplift displacement considered in the experiments. Hence, the reinforced foundation shows low ultimate bearing capacity probably because the geogrid reduces the density of the ground and may be the strength of the geogrid is not mobilized in the range of the uplift displacement considered in the experiments.

\subsection{Statistical Analysis of Influencing Factors on Bearing Capacity}

3.3.1. Factor Interaction Analysis. Interaction refers to a comprehensive effect on indicators when some factors impact each other. Different from the effect of a single factor on the index, the combined factors can also affect each index. In general, the interaction between factors can be represented intuitively by graphics. For simplicity, it is assumed that no matter what level of factor $B$ is, $A$ is the same in different conditions; then, it can be concluded that there is no interaction between factor $A$ and factor $B$. As displayed in Figure 8 , under different displacement and deformation, the 


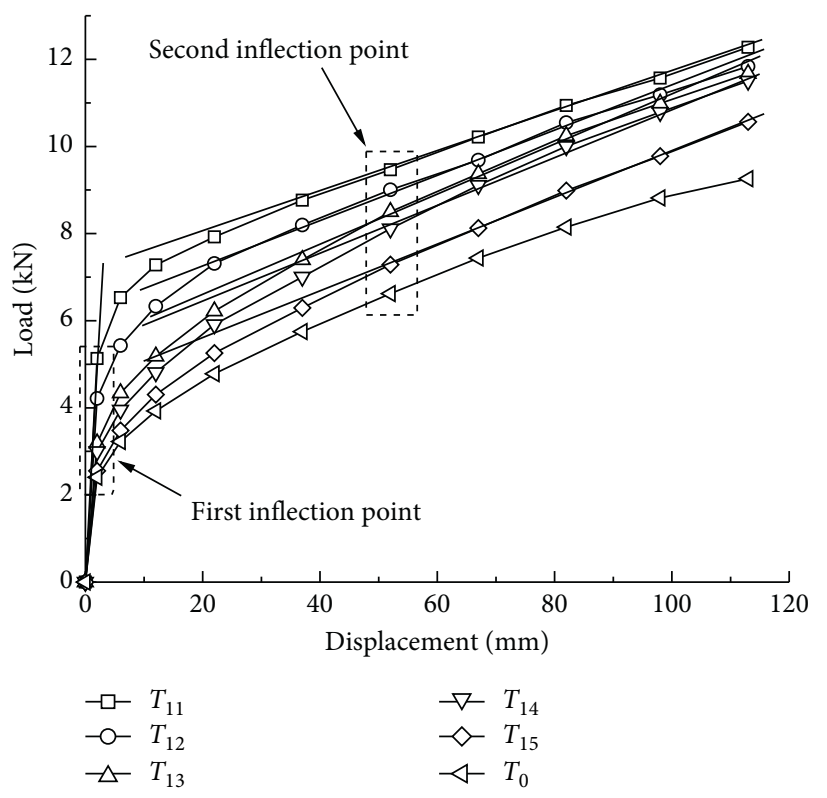

(a)

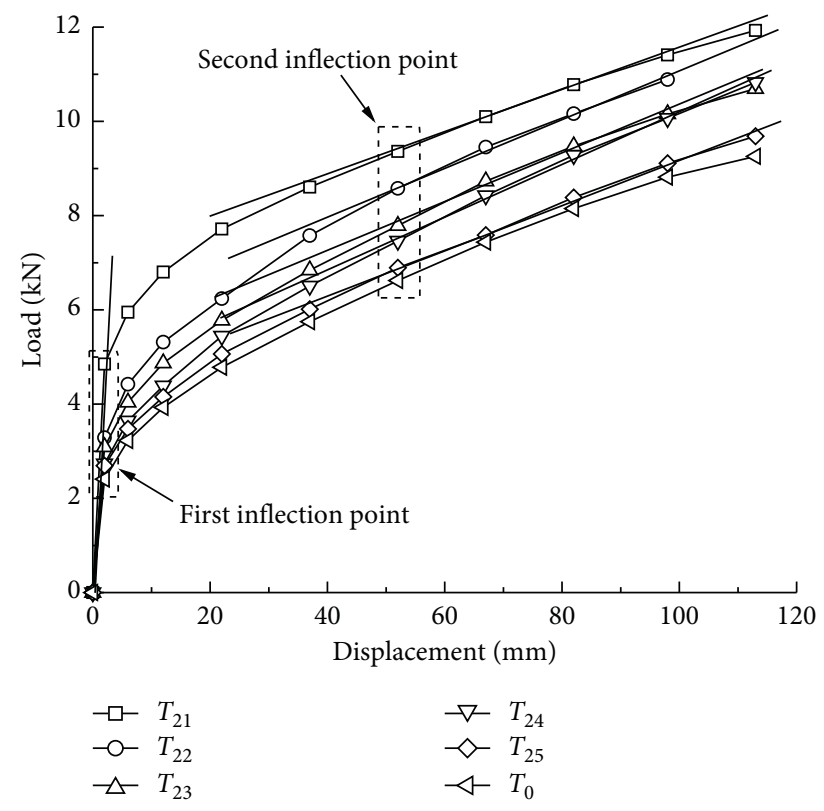

(b)

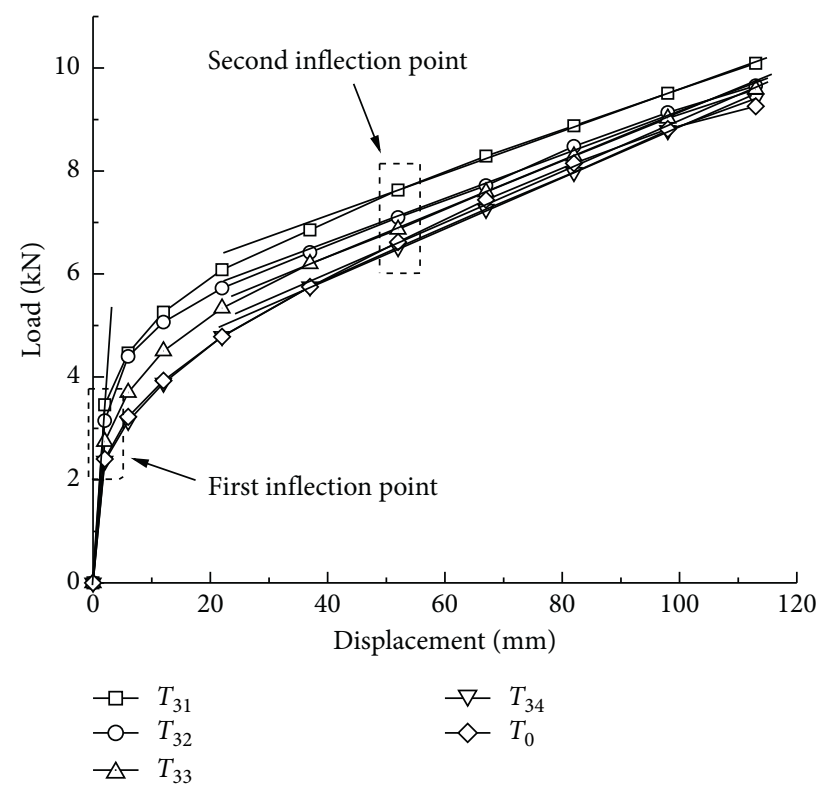

(c)

FIGURE 6: Uplift load and displacement curve with different layout spacing: (a) BPG, (b) SPG, and (c) geotextile.

bearing capacity obtained at different levels of factor $A$ and $B$ is generally parallel. Therefore, it is considered that there are no interaction effects between factor $A$ and factor $B$ in this study for simple.

3.3.2. Statistics of the Test Mean Values at the Same Levels. The stable load in the loading test is the bearing capacity of foundation in the corresponding state. Under fixed displacement, the experimental results of uplift bearing capacity at $a_{i}$ and $b_{j}$ levels are expressed by $y_{i j}$, and the average bearing capacity of experimental results (the number of experiments is $s$ ) at the $i$ level of factor $A$ is expressed by $\bar{y}_{i}$; then,

$$
\bar{y}_{i,}=\frac{\sum_{j=1}^{s} y_{i j}}{s} .
$$

For the sake of intuition, the increment of average bearing capacity is defined as follows:

$$
\Delta y_{i,}=\bar{y}_{i,}-y_{0}
$$

where $y_{0}$ is the uplift bearing capacity of the unreinforced aeolian sand foundation. 


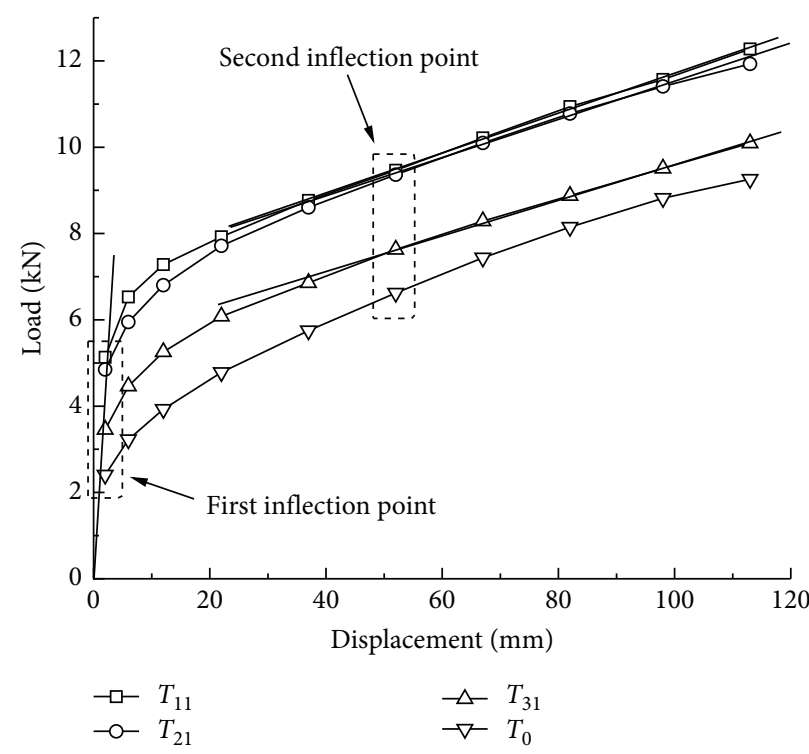

(a)

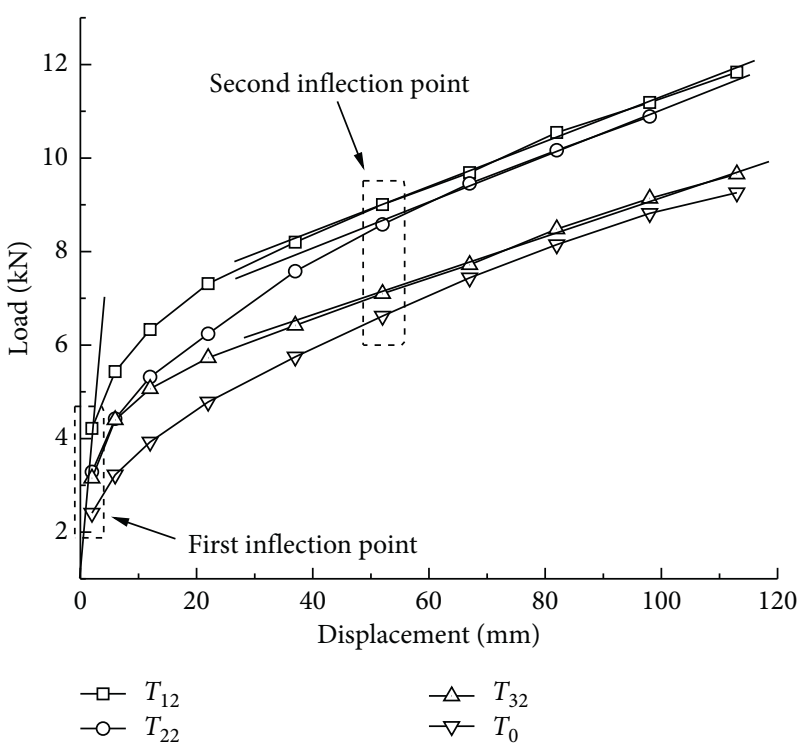

(b)

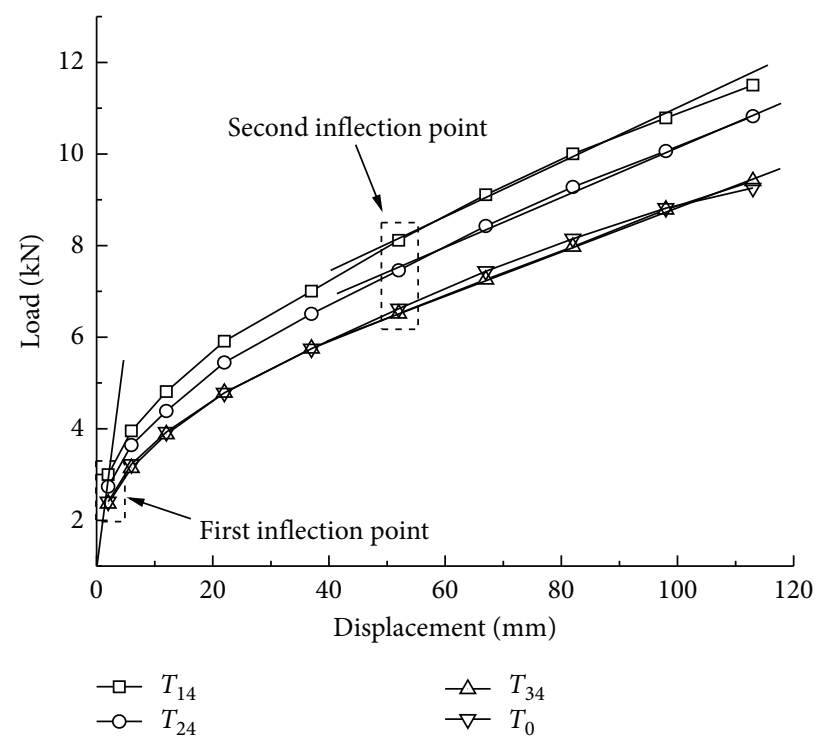

(c)

FIGURE 7: Uplift load and displacement curve with different reinforcement materials. (a) Layout spacing $50 \mathrm{~mm}$. (b) Layout spacing $100 \mathrm{~mm}$. (c) Layout spacing $200 \mathrm{~mm}$.

In the same way, the average bearing capacity increment at the $j$ level of factor $B\left(b_{j}\right)$ can be calculated (the number of experiments is $r$ ):

$$
\Delta y_{, j}=\bar{y}_{, j}-y_{0},
$$

in which

$$
\bar{y}_{, j}=\frac{\sum_{i=1}^{r} y_{i j}}{r}
$$

The increment curve of the uplift load and displacement is shown in Figure 9. The average bearing capacity increment and displacement curve of different reinforced materials are presented. It can be seen that, in the small deformation stage, the bearing capacity increment increases rapidly with the increase of displacement, and the reinforcement become obvious. With the continuous increase of displacement, the average bearing capacity increment of materials $a_{1}$ and $a_{2}$ tends to be stable, and the bearing capacity increment of material $a_{3}$ decreases slowly. This agrees with the field prototype test results of [32], and this is mainly caused by the relaxation of the reinforcement, which requires a large displacement of the foundation to show the reinforcement effect. Material $a_{1}$ has the largest increment of bearing capacity and the best reinforcement effect, followed by $a_{2}$, and this is mainly affected by the difference of material mesh size. Furthermore, although the mechanical properties of the grid strips of SPG are better than those of BPG, the dimension of 
TABle 3: Model test data.

\begin{tabular}{|c|c|c|c|c|}
\hline Foundation type & $\begin{array}{l}\text { Experimental } \\
\text { number }\end{array}$ & $\begin{array}{l}\text { Reinforcement spacing } \\
(\mathrm{mm})\end{array}$ & $\begin{array}{l}\text { Ultimate bearing capacity } T_{\mathrm{u}} \\
(\mathrm{kN})\end{array}$ & $\begin{array}{c}\text { Ratio } \\
K\end{array}$ \\
\hline Aeolian sand foundation & $T_{0}$ & $\begin{array}{l}\text { Without reinforcement } \\
\text { material }\end{array}$ & 6.62 & - \\
\hline \multirow{5}{*}{$\begin{array}{l}\text { Aeolian sand BPG reinforced composite } \\
\text { foundation }\end{array}$} & $T_{11}$ & 50 & 9.47 & 1.43 \\
\hline & $T_{12}$ & 100 & 9.00 & 1.36 \\
\hline & $T_{13}$ & 150 & 8.50 & 1.28 \\
\hline & $T_{14}$ & 200 & 8.11 & 1.23 \\
\hline & $T_{15}$ & 300 & 7.29 & 1.10 \\
\hline \multirow{5}{*}{$\begin{array}{l}\text { Aeolian sand SPG reinforced composite } \\
\text { foundation }\end{array}$} & $T_{21}$ & 50 & 9.36 & 1.41 \\
\hline & $T_{22}$ & 100 & 8.58 & 1.30 \\
\hline & $T_{23}$ & 150 & 7.79 & 1.18 \\
\hline & $T_{24}$ & 200 & 7.46 & 1.13 \\
\hline & $T_{25}$ & 300 & 6.89 & 1.04 \\
\hline \multirow{4}{*}{$\begin{array}{l}\text { Aeolian sand geotextile reinforced composite } \\
\text { foundation }\end{array}$} & $T_{31}$ & 50 & 7.63 & 1.15 \\
\hline & $T_{32}$ & 100 & 7.10 & 1.07 \\
\hline & $T_{33}$ & 150 & 6.87 & 1.04 \\
\hline & $T_{34}$ & 200 & 6.51 & 0.98 \\
\hline
\end{tabular}

SPG is $40 \mathrm{~mm} \times 40 \mathrm{~mm}$, which is smaller than BPG with dimension of $80 \mathrm{~mm} \times 80 \mathrm{~mm}$. As a result, $K$ of SPG is larger than that of BPG.

Figure 10 shows the curve of average bearing capacity and layout spacing under different displacements. The figure shows the effects of a number of reinforcement layers. It can be seen from the figure that the denser the reinforcement material, the better the reinforcement effect. In the small displacement stage, the average increases with the increase of displacement. The denser the reinforcement, the higher the average value. As the displacement continues increasing, the average of the composite foundation with a larger spacing of reinforcement materials continues to increase. In contrast, the average of the composite foundation with a dense spacing of reinforcement tends to be gentle or decrease slowly. The reason can be attributed to the inapparent reinforcement induced by geotextile when the space is smaller and the deformation is larger (shown in Figure 6). The average is still larger than that of composite foundation with larger spacing of reinforcement.

The results show that BPG has the best reinforcement effect among three different geotechnical materials, and the bearing capacity of the composite foundation model is positively correlated with the spacing of the reinforced materials. The uplift resistance is getting larger when the space of geotextile is getting smaller.

In order to investigate the effect of reinforcement with different spacing, $j$ level $\left(b_{j}\right)$ of factor $B$ is defined as follows:

$$
\Delta \bar{Y}_{, j}=\Delta \bar{y}_{, j} \frac{b_{j}}{L},
$$

where $b_{j}$ is the layout spacing of reinforcement, unit: $\mathrm{mm}$, and foundation buried depth $L=1300 \mathrm{~mm}$.

The variable $\Delta \bar{Y}_{, j}$ reflects the contribution of each layer of reinforcement to the increment of bearing capacity and also reflects the reinforcement effect of the unit reinforcement material, which can be regarded as an economic index.
Figure 11 shows the curves of each layer of reinforcement to the increment of bearing capacity and layout spacing under different displacement loads. With the increase spacing of reinforcement, the average contribution of each layer of reinforcement to the increment of bearing capacity increases first and then decreases. The appropriate layout spacing of the reinforcement material is conducive to show the effect of reinforcement. In the case of dense reinforcement $\left(b_{j}\right.$ is less than $\left.100 \mathrm{~mm}\right)$, the reinforcement becomes obvious in the small displacement stage, and the bearing capacity limitedly increases with the continuous increase of displacement. While the layout spacing of reinforcement is a little larger $\left(b_{j}\right.$ is larger than $\left.150 \mathrm{~mm}\right)$, the reinforcement has a certain contribution to the bearing capacity at the small displacement stage and increases continuously with the increase of displacement, so the reinforcement effect of reinforcement can be fully exerted. When the spacing of reinforced materials in the model test is $200 \mathrm{~mm}$, the comprehensive benefit is the best.

3.3.3. Analysis of Variance of Bearing Capacity. In order to deeply evaluate the influence of factors on the uplift performance of composite foundation and foundation model, variance analysis of test results is conducted. The total sum of the square of variance [33] is used to describe the fluctuation of data. The total variance sum of squares is given as

$$
S_{T}=\sum_{i=1}^{r} \sum_{j=1}^{s}\left(y_{i j}-\bar{y}\right)^{2},
$$

where $\bar{y}$ is the average value of the total test results, which is defined by

$$
\bar{y}=\frac{\sum_{i=1}^{r} \sum_{j=1}^{s} y_{i j}}{r s} .
$$

Since there is no interaction between factors, there are three reasons for data fluctuation when the sum of squares 

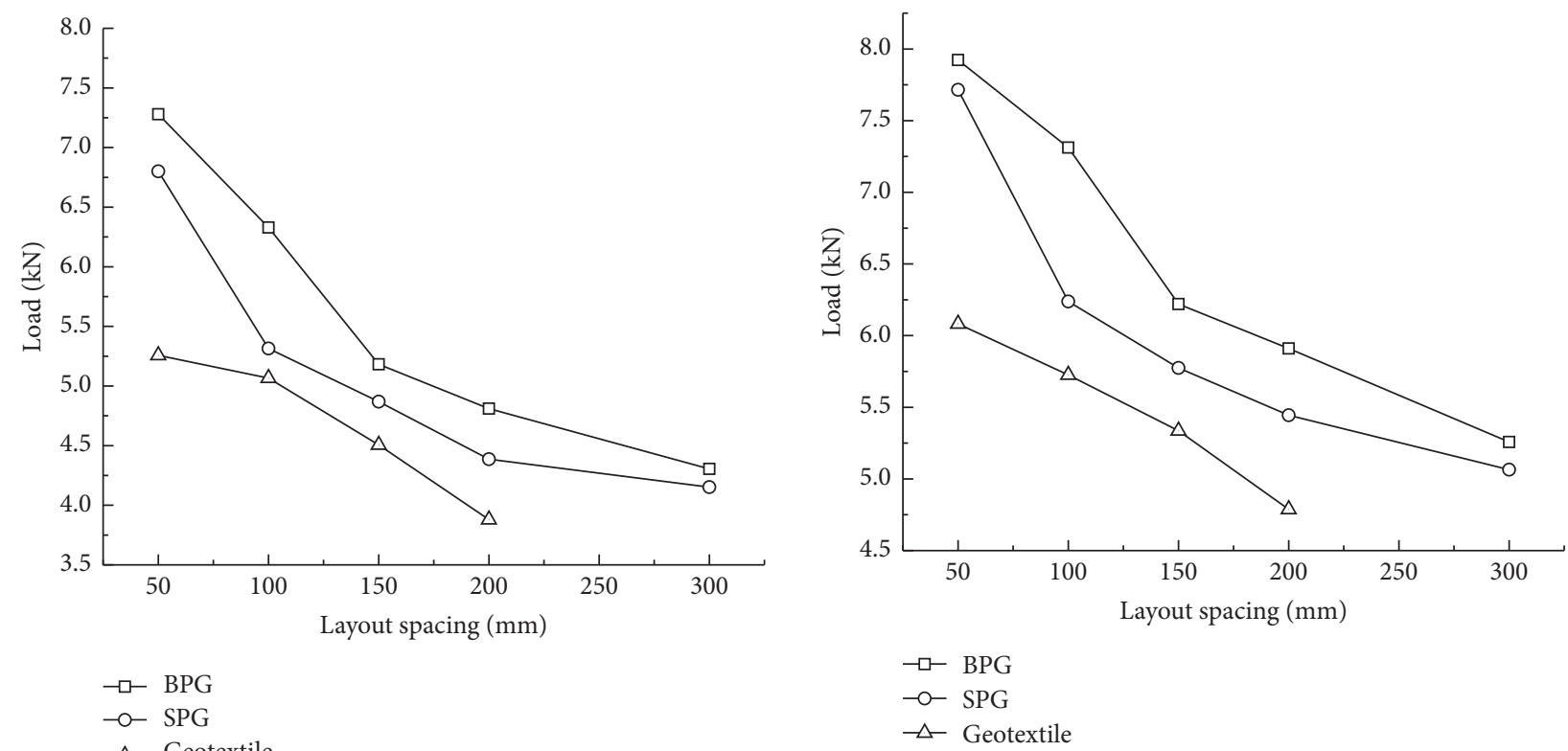

(a)

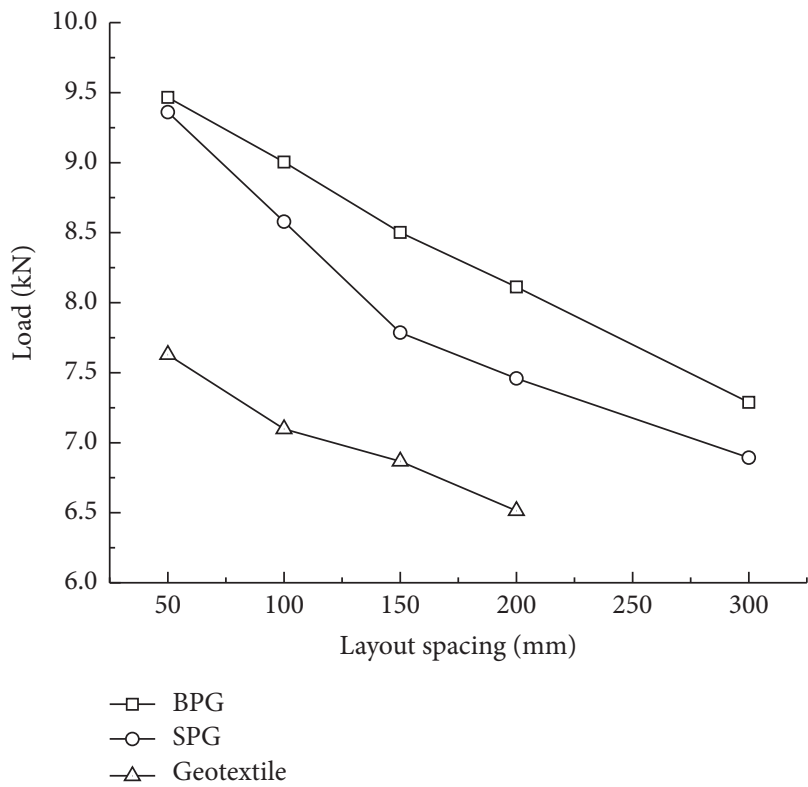

(c)

(b)

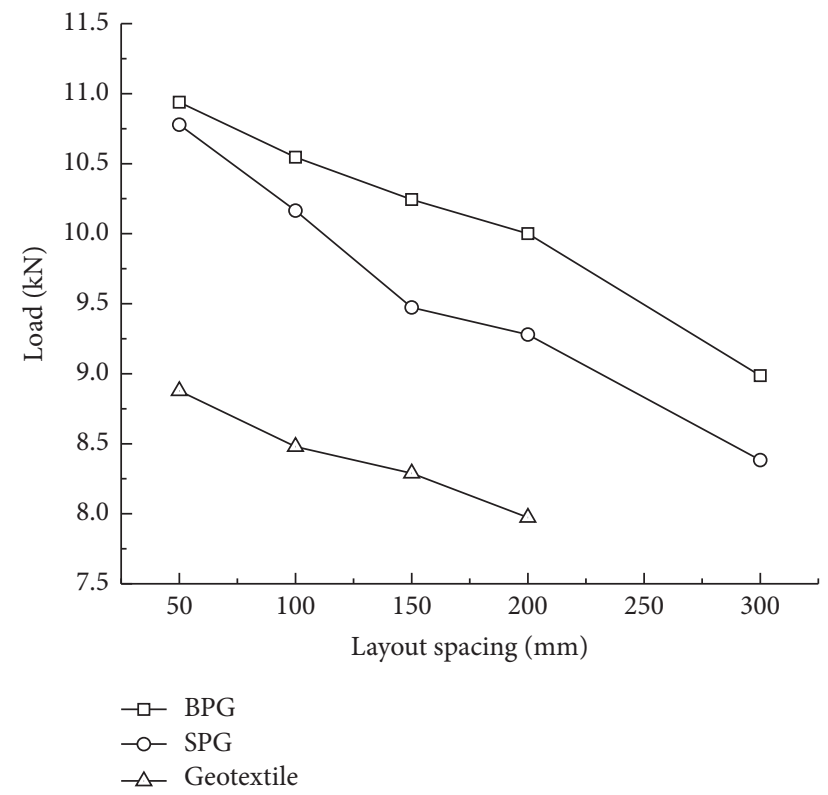

(d)

Figure 8: Schematic diagram of the interaction between factors $A$ and $B$ under different displacements: (a) $12 \mathrm{~mm}$, (b) $22 \mathrm{~mm}$, (c) $52 \mathrm{~mm}$, and (d) $82 \mathrm{~mm}$.

decomposition is performed: the difference of factor $A$, the difference of factor $B$, and the random error [34]. Therefore, the total sum of the square of the data variance can be decomposed into three parts:

$$
S_{T}=S_{A}+S_{B}+S_{e},
$$

where $S_{A}, S_{B}$, and $S_{e}$ are defined as factor $A$, factor $B$, and the error's sum of the square of variance, respectively, and their calculation formulas are as follows:

$$
\begin{aligned}
& S_{A}=\sum_{i=1}^{r} s\left(\bar{y}_{i}-\bar{y}\right)^{2}, \\
& S_{B}=\sum_{j=1}^{s} r\left(\bar{y}_{, j}-\bar{y}\right)^{2}, \\
& S_{E}=\sum_{i=1}^{r} \sum_{j=1}^{s}\left(y_{i j}-\bar{y}_{i,}-\bar{y}_{, j}+\bar{y}\right)^{2} .
\end{aligned}
$$




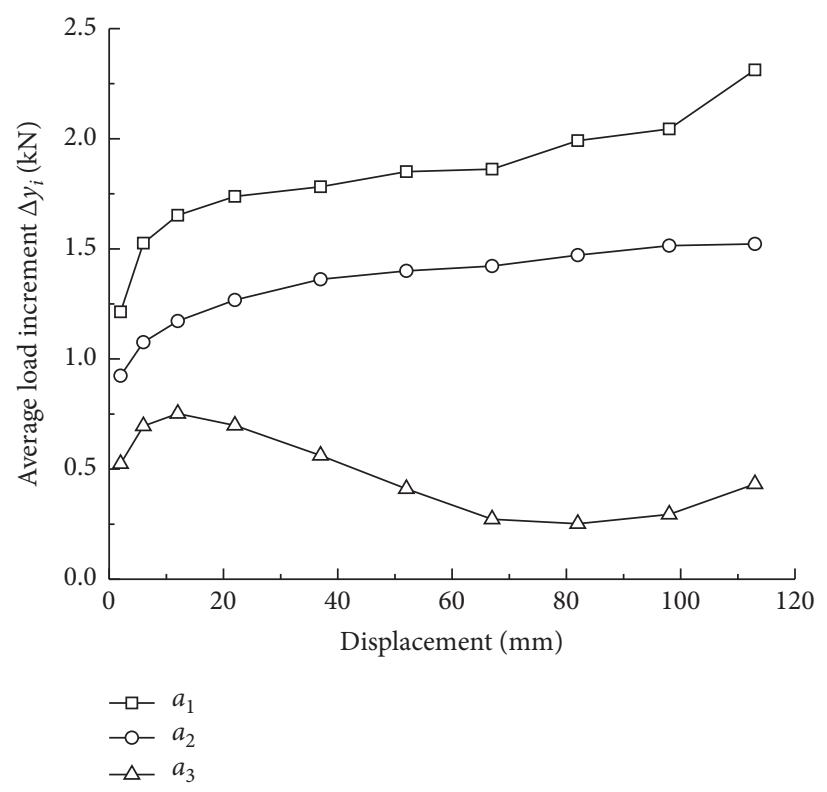

FIgURE 9: Influence of different materials on bearing capacity.

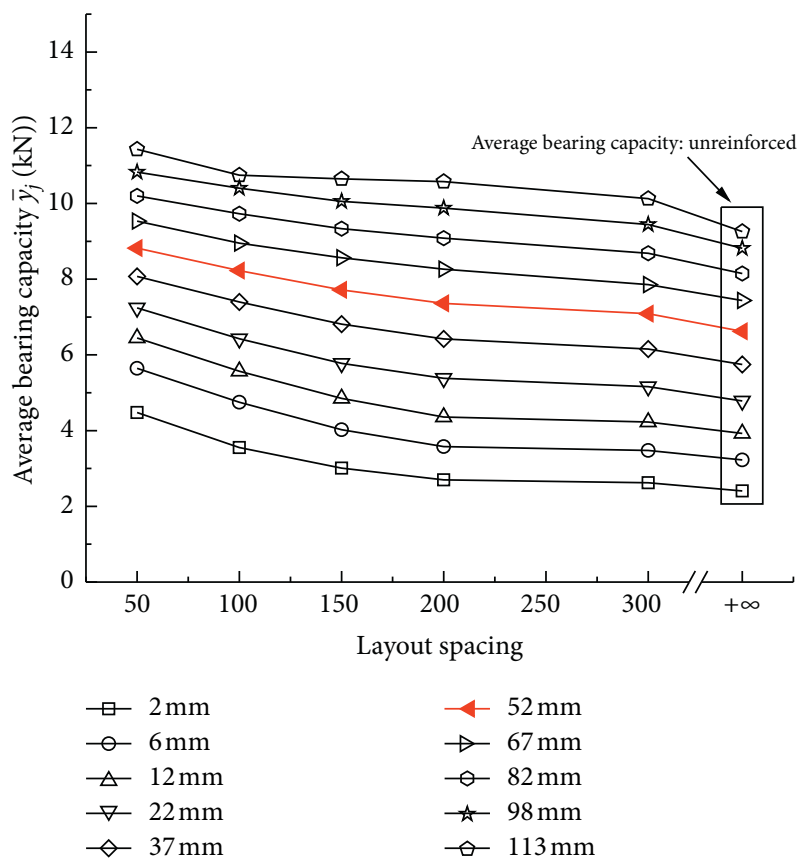

FIGURE 10: Influence of different spacing on bearing capacity.

Divide the sum of squares of $S$ variances by the degrees of freedom $f$ to obtain the mean square sum $V$, i.e., $V=S / f$. Then, the $F$ ratio is used to evaluate the influence of each factor on bearing capacity, which is defined as the ratio of the mean square sum of each factor and the mean square sum of errors, namely, $F_{A}=V_{A} / V_{E}$ and $F_{B}=V_{B} / V_{E}$.

The contribution rate $\rho$ is used to evaluate the effect of the factor, and the formula is as follows:

$$
\rho=\frac{100\left(S-f \cdot V_{E}\right)}{S_{T}} .
$$

The results analysis of variance is presented in Table 4 . $F_{A}$ and $F_{B}$ obey $F$ distributions with degrees of freedom of $(2,8)$ and $(4,8)$, respectively. The quantile of $F$ distribution can be used to divide the ratio. $F$ and contribution rate $\rho$ of factors $A$ and $B$ under different displacements are displayed in Figure 12.

The influence of factor $A$ on the bearing capacity increases with the increase of displacement. The relationship between $F_{A}, \rho_{A}$, and displacement is approximately linear, which indicates that the influence of the reinforced material is significant, and the reinforcement effect continues 


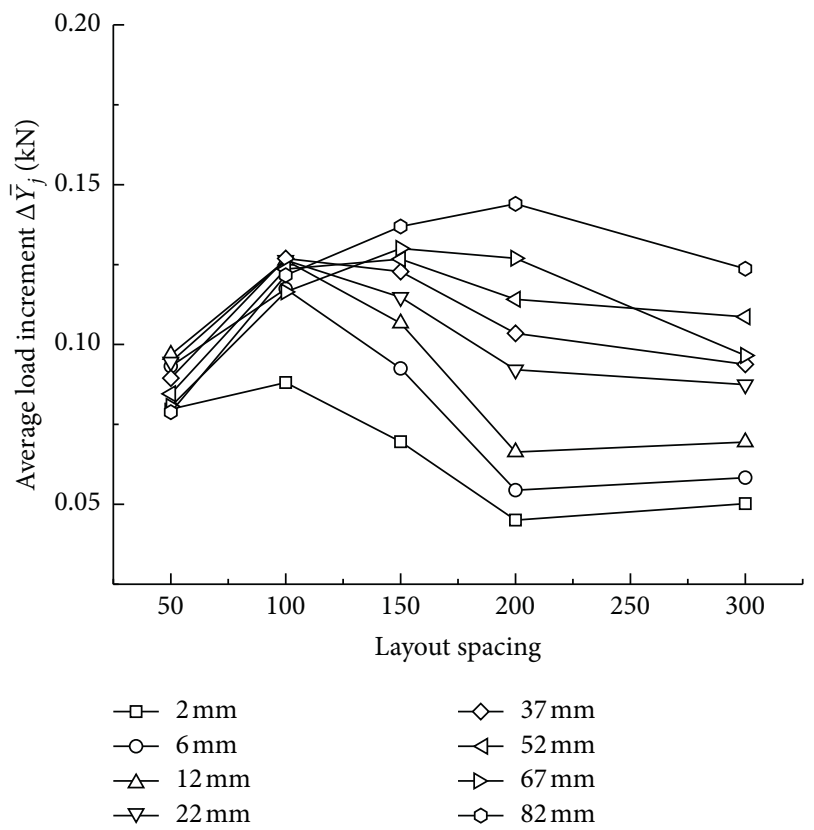

Figure 11: Influence of each layer of the geotechnical material on bearing capacity increment.

TABLE 4: Analysis of the variance table.

\begin{tabular}{|c|c|c|c|c|c|c|c|c|c|c|c|}
\hline \multirow[t]{2}{*}{ Displacement (mm) } & \multicolumn{4}{|c|}{ Sum of the square of deviance $S$} & \multicolumn{3}{|c|}{ Mean square sum $V$} & \multicolumn{2}{|c|}{$F$ ratio } & \multicolumn{2}{|c|}{$\begin{array}{c}\text { Contribution } \\
\text { rate } \rho(\%)\end{array}$} \\
\hline & $S_{T}$ & $S_{A}$ & $S_{B}$ & $S_{E}$ & $V_{A}$ & $V_{B}$ & $V_{E}$ & $F_{A}$ & $F_{B}$ & $\rho_{A}$ & $\rho_{B}$ \\
\hline 2 & 9.21 & 1.20 & 7.06 & 0.95 & 0.60 & 1.77 & 0.12 & 5.02 & 14.80 & 10.4 & 71.4 \\
\hline 6 & 12.66 & 1.69 & 9.87 & 1.10 & 0.85 & 2.47 & 0.14 & 6.14 & 17.94 & 11.1 & 73.5 \\
\hline 12 & 13.21 & 2.05 & 10.20 & 0.96 & 1.02 & 2.55 & 0.12 & 8.50 & 21.19 & 13.7 & 73.6 \\
\hline 22 & 12.21 & 2.72 & 8.57 & 0.92 & 1.36 & 2.14 & 0.12 & 11.82 & 18.61 & 20.3 & 66.3 \\
\hline 37 & 11.90 & 3.88 & 7.19 & 0.83 & 1.94 & 1.80 & 0.10 & 18.61 & 17.22 & 30.9 & 57.1 \\
\hline 52 & 11.97 & 5.47 & 5.74 & 0.76 & 2.74 & 1.43 & 0.10 & 28.64 & 15.01 & 44.0 & 44.6 \\
\hline 67 & 12.51 & 6.72 & 4.97 & 0.81 & 3.36 & 1.24 & 0.10 & 33.12 & 12.26 & 52.1 & 36.5 \\
\hline 82 & 12.81 & 7.94 & 4.09 & 0.78 & 3.97 & 1.02 & 0.10 & 40.77 & 10.48 & 60.4 & 28.8 \\
\hline 97 & 12.11 & 8.01 & 3.31 & 0.79 & 4.01 & 0.83 & 0.10 & 40.64 & 8.38 & 64.5 & 24.0 \\
\hline 113 & 12.28 & 8.97 & 2.66 & 0.66 & 4.49 & 0.66 & 0.08 & 54.65 & 8.09 & 71.7 & 19.1 \\
\hline $\begin{array}{l}\text { Degree of freedom } f \\
F \text { Distribution }\end{array}$ & & & & & $\begin{array}{r}f_{A}=2 \\
2,8)=\end{array}$ & $\begin{array}{l}=4 \text {, a } \\
\text { and }\end{array}$ & $\begin{array}{l}{ }_{E}=8 \\
(4,8)\end{array}$ & & & & \\
\hline
\end{tabular}

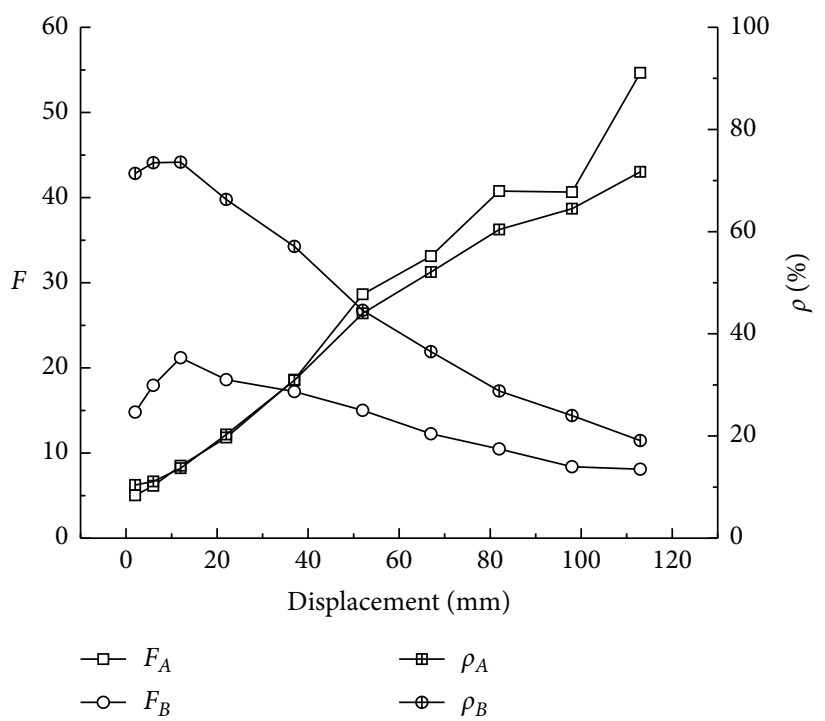

Figure 12: $F$ distribution and contribution rate $\rho$ displacement curve. 
increasing. The influence of factor $B$ increases first and then decreases with the increase of displacement, and the relationship between $F_{B}, \rho_{B}$, and displacement is also approximately linear, when the displacement $s$ is larger than $12 \mathrm{~mm}$ and the reinforcement effect decreases overall trends. When the displacement $s$ is equal to $52 \mathrm{~mm}$, the contribution rate of factor $A$ and factor $B$ is equivalent, the contribution rate of factor $B$ is greater than that of factor $A$ at small displacement, and the contribution rate of factor $A$ is greater than factor $B$ when the displacement $s$ is greater than $52 \mathrm{~mm}$.

In the whole loading process, $F_{A}>F_{0.95}(2,8)$ and $F_{B}>F_{0.95}(4,8)$. At the significant level of 0.05 , the influence of the factors, $A$ and $B$, on bearing capacity is significant.

\section{Conclusions}

Uplift loading tests of aeolian sand-reinforced uplift composite ground and foundation model are conducted on different reinforced geotechnical material sand layout spacing conditions. The influence of reinforcement materials and spacing on the bearing capacity of the extended foundation is analyzed. The main conclusions are as follows:

(1) The curve of bearing capacity and displacement does not show steep drops. The corresponding displacements of two inflection points are $2 \mathrm{~mm}$ and $52 \mathrm{~mm}$, respectively. The initial and later stages of loading are approximately linear, and the curve between two inflection points presents a plastic state.

(2) According to the second inflection point, the ultimate uplift capacity of model foundation can be significantly improved after the reinforcement treatment of geotechnical materials for aeolian sand. Compared with the nonreinforced soil, the ultimate uplift capacity (when the uplift deformation is $52 \mathrm{~mm}$ ) of BPG with the space of $50 \mathrm{~mm}$ and $300 \mathrm{~mm}$ is increased by $10 \%$ and $43 \%$ and that of SPG is $4 \%$ to $41 \%$. The uplift bearing capacity increase of geotextile is from $-1.6 \%$ to $15 \%$ with the space of $50 \mathrm{~mm}$ and $200 \mathrm{~mm}$. When the layout spacing is the same, the improvement effect of BPG is the best, followed by SPG and geotextile.

(3) The type and layout spacing of reinforced materials have a significant influence on the uplift bearing capacity of the composite foundation model, and the whole loading process contributes to the enhancement of bearing capacity. When the displacement is less than $52 \mathrm{~mm}$, the contribution of layout spacing to uplift bearing capacity is higher than that provided by materials.

(4) Among the five kinds of layout spacing of composite foundation in this tests, the comprehensive effect of the reinforcement material per layer on uplift bearing capacity of model foundation is the best when the spacing is $200 \mathrm{~mm}$. The smaller the spacing, the earlier and faster the reinforcement effect and the shorter the curve segment reflecting the relationship between bearing capacity and displacement.
(5) It should be pointed out that the results are obtained from indoor model experiments, and the validation of the test results using numerical modeling and prototype test can be a part of the future study.

\section{Data Availability}

The data used to support the findings of this study are included within the article.

\section{Conflicts of Interest}

The authors declare that they have no conflicts of interest.

\section{Acknowledgments}

This study was financially supported by the National Natural Science Foundation of China (Grant no. 52079002).

\section{References}

[1] G. G. Meyerhof and J. I. Adams, "The ultimate uplift capacity of foundations," Canadian Geotechnical Journal, vol. 5, no. 4, pp. 225-244, 1968.

[2] G. M. Latha and A. Somwanshi, "Bearing capacity of square footings on geosynthetic reinforced sand," Geotextiles and Geomembranes, vol. 27, no. 4, pp. 281-294, 2009.

[3] J. Lovisa, S. K. Shukla, and N. Sivakugan, "Behaviour of prestressed geotextile-reinforced sand bed supporting a loaded circular footing," Geotextiles and Geomembranes, vol. 28, no. 1, pp. 23-32, 2010.

[4] A. K. Choudhary, J. N. Jha, and K. S. Gill, "Laboratory investigation of bearing capacity behaviour of strip footing on reinforced flyash slope," Geotextiles and Geomembranes, vol. 28, no. 4, pp. 393-402, 2010.

[5] H. Ahmadi and M. Hajialilue-Bonab, "Experimental and analytical investigations on bearing capacity of strip footing in reinforced sand backfills and flexible retaining wall," Acta Geotechnica, vol. 7, no. 4, pp. 357-373, 2012.

[6] M. El Sawwaf and A. Nazir, "Behavior of eccentrically loaded small-scale ring footings resting on reinforced layered soil," Journal of Geotechnical and Geoenvironmental Engineering, vol. 138, no. 3, pp. 376-384, 2012.

[7] B. F. Tanyu, A. H. Aydilek, A. W. Lau, T. B. Edil, and C. H. Benson, "Laboratory evaluation of geocell-reinforced ravel subbase over poor subgrades," Geosynthetics International, vol. 20, no. 2, pp. 46-71, 2013.

[8] X. Yang, J. Han, D. Leshchinsky, and R. L. Parsons, “A three-dimensional mechanistic-empirical model for geocell-reinforced unpaved roads," Acta Geotechnica, vol. 8, no. 2, pp. 201-213, 2013.

[9] K. Amin and K. Jyant, "Bearing capacity computation for a ring foundation using the stress characteristics method," Computers and Geotechnics, vol. 89, 2017.

[10] S. Dash, N. R. Krishnaswamy, and K. Rajagopal, "Bearing capacity of strip footings supported on geocell-reinforced sand," Geotextiles and Geomembranes, vol. 19, no. 4, pp. 235-256, 2001.

[11] G.-l. Yuan, S.-m. Li, G.-a. Xu, W. Si, Y.-f. Zhang, and Q.-j. Shu, "The anti-deformation performance of composite foundation of transmission tower in mining subsidence area," Procedia Earth and Planetary Science, vol. 1, no. 1, pp. 571576, 2009. 
[12] K. M. Kouzer and J. Kumar, "Vertical uplift capacity of two interfering horizontal anchors in sand using an upper bound limit analysis," Computers and Geotechnics, vol. 36, no. 6, pp. 1084-1089, 2009.

[13] K. M. Kouzer and J. Kumar, "Vertical uplift capacity of equally spaced horizontal strip anchors in sand," International Journal of Geomechanics, vol. 9, no. 5, pp. 230-236, 2009.

[14] S. N. M. Tafreshi and A. R. Dawson, "Comparison of bearing capacity of a strip footing on sand with geocell and with planar forms of geotextile reinforcement," Geotextiles and Geomembranes, vol. 28, no. 1, pp. 72-84, 2010.

[15] S. N. Moghaddas Tafreshi, S. Javadi, and A. R. Dawson, "Influence of geocell reinforcement on uplift response of belled piles," Acta Geotechnica, vol. 9, no. 3, pp. 513-528, 2014.

[16] M. Abu-Farsakh, Q. Chen, and R. Sharma, “An experimental evaluation of the behavior of footings on geosynthetic-reinforced sand," Soils and Foundations, vol. 53, no. 2, pp. 335-348, 2013.

[17] M. S. Keskin, "Model studies of uplift capacity behavior of square plate anchors in geogrid-reinforced sand," Geomechanics and Engineering, vol. 8, no. 4, pp. 595-613, 2015.

[18] Y. Tavangar and I. Shooshpasha, "Experimental and numerical study of bearing capacity and effect of specimen size on uniform sand with medium density, reinforced with nonwoven geotextile," Arabian Journal for Science and Engineering, vol. 41, no. 10, pp. 4127-4137, 2016.

[19] E. Cicek, E. Guler, and T. Yetimoglu, "Effects of the first reinforcement depth on different types of geosynthetics," Scientia Iranica, vol. 26, no. 1, pp. 167-177, 2017.

[20] A. Ghosh and A. K. Bera, "Effect of geotextile ties on uplift capacity of anchors embedded in sand," Geotechnical \& Geological Engineering, vol. 28, no. 5, pp. 567-577, 2010.

[21] A. H. Boushehrian, N. Hataf, and A. Ghahramani, "Numerical study of cyclic behavior of shallow foundations on sand reinforced with geogrid and grid-anchor," World Academy of Science Engineering and Technology, vol. 72, no. 58, pp. 607-610, 2009.

[22] A. Das and A. K. Bera, "Ultimate uplift capacity of bell-shaped anchor in river sand using finite element software "ABAQUS”' Geotechnical \& Geological Engineering, vol. 37, no. 5, pp. 4121-4133, 2019.

[23] IEEE Std 691-2001, IEEE Guide for Transmission Structure Foundation Design and Testing, The Institute of Electrical and Electronics Engineers, Inc., Piscataway, NJ, USA, 2001.

[24] B. C. Chattopadhyay and P. J. Pise, "Uplift capacity of piles in sand," Journal of Geotechnical Engineering, vol. 112, no. 9, pp. 888-904, 1986.

[25] E. A. Dickin, "Uplift behavior of horizontal anchor plates in sand," Journal of Geotechnical Engineering, vol. 114, no. 11, pp. 1300-1317, 1988.

[26] E. A. Dickin and C. F. Leung, "Performance of piles with enlarged bases subject to uplift forces," Canadian Geotechnical Journal, vol. 27, no. 5, pp. 546-556, 1990.

[27] K. L. Teh, D. J. White, Y. K. Chow, and C. F. Leung, "A comparison of the bearing capacity of flat and conical circular foundations on sand," Géotechnique, vol. 58, no. 10, pp. 781-792, 2008.

[28] R. K. Rowe and E. H. Davis, "The behaviour of anchor plates in clay," Géotechnique, vol. 32, no. 1, pp. 9-23, 1982.

[29] H. G. Poulos and E. H. Davis, Pile Foundations Analysis and Design, John Wiley \& Sons, Hoboken, NJ, USA, 1980.

[30] W. B. Liu, J. Zhou, Y. H. Su, and L. Liu, "Uplift test study on reinforced aeolian sand (I) - properties and uplift model tests on spread foundation," Chinese Journal of Rock Mechanics and Engineering, vol. 22, no. 7, pp. 1161-1168, 2003.

[31] F. H. Kulhawy and A. Hirany, Interpretation of Load Tests on Drilled Shafts-Part 2: Axial Uplift Foundation Engineering, ASCE, Reston, VA, USA, 1989.

[32] Z. Qian, X. Lu, and S. Ding, "Experiments on pad and chimney foundation in reinforced aeolian sand under uplift combined with horizontal loads," Chinese Journal of Geotechnical Engineering, vol. 33, no. 3, pp. 373-379, 2011.

[33] D. A. Freedman, R. Pisani, and R. A. Purves, Statistics, W. W. Norton, Inc, New York, NY, USA, 1978.

[34] J. Neter, W. Wasserman, and G. A. Whitmore, Applied Statistics, Allyn \& Bacon, Boston, MA, USA, 2nd edition, 1982. 